\title{
Comparison of static balance and mobility between nursing home residents and community-dwelling elderly.
}

\author{
Livia Marcondes Faber ${ }^{1}$, Lara Alves Moreira², Marcos Eduardo Scheicher ${ }^{3}$
}

\begin{abstract}
Background: Postural control is considered to be a complex motor skill derived from the interaction of multiple sensorimotor processes. Objectives: To compare the static balance and mobility of nursing home residents with community-dwelling elderly and verify which confounders imply in a worse postural balance on nursing home residents. Methods: Were included elderly aged 60 and more, both sexes, living at nursing homes (NHs) and at the community. The static balance was evaluated by a force platform and the mobility by the Timed Up and Go test (TUG). The confounders available were length of institutionalization, age, gender, body mass index, number of falls and number of medication. Comparisons were made by unpaired t-tests and by the Mann-Whitney test. The risk of falls was evaluated by Fisher's Exact Test. Pearson or Spearman correlation analysis was performed to identify the independent variables with a significant relationship with the dependent variables. The simple linear regression analysis and R2 was analyzed to ascertain the coefficient of determination of the percentage variation. A value of $p \leq 0.05$ was considered significant. Results: 21 nursing home residents and 21 community-dwelling elderly were included. The NHs residents presented significantly higher values of COP oscillation than the community group (total displacement: $p=0.0002$; mean velocity: $p=0.001,95 \%$ ellipse area: $p=0,04$, and standard deviation in the frontal plane: $p=0.01$ ). The NHs group presented longer time to perform the TUG test than the community group (17.28 $\pm 4.5 \mathrm{~s}$ and $13.21 \pm 3.9 \mathrm{~s}, \mathrm{p}=0.002)$. Was observed that the number of medications showed a significant correlation with the TUG ( $r=0.52 ; p=0.01)$, and none variable showed correlation with the static balance. Conclusion: The results showed that the nursing home residents with a normal cognitive condition had greater center of gravity oscillation, worse mobility, and higher risk of falls than community elders. In addition, it was found that in nursing home residents, the ingestion of five or more drugs had relation with mobility.
\end{abstract}

Key-words: Elderly; Postural Balance; Nursing ome.

\section{INTRODUCTION}

Postural control is considered to be a complex motor skill derived from the interaction of multiple sensorimotor processes ${ }^{1}$.

Studies in elderly established that many aspects of motor control are affected by aging, causing slower and less coordinated movements. ${ }^{2,3}$ The decline in postural stability is caused by a decrease in the sensitivity of neural receptors, a decrease in the speed of the central processing systems of the brain, cognitive decline, and the decreased potential of power production in motor systems. ${ }^{4}$ One of the complications of changes in postural control is the occurrence of falls, which, besides to be responsible for the reduction of activities of daily living, may lead to the institutionalization of the elderly. ${ }^{5}$

Seniors living in nursing homes ( $\mathrm{NHs}$ ) are a complex population, characterized by high prevalence of dependency in activities of daily living (ADLs), multimorbidity, and polypharmacy. ${ }^{6}$ When compared with community-dwelling elderly, nursing home residents have fewer opportunities to independently participate in activities and tasks of daily living (e.g., domestic or recreational) that could minimize and/or alleviate the effects of aging. ${ }^{7}$ Ikezoe et al. (2013) showed that the elderly women living in nursing homes spent $56.9 \%$ of their daytime sitting and $17.4 \%$ lying down, suggesting that this population spends a lot of time sedentary and inactive, even during the daytime? ${ }^{7}$.

Nursing home residents present a reduction in their physical abilities (muscular strength, aerobic resistance, and flexibility), which, together with a sedentary lifestyle, influence their daily function, altering their gait and balance ${ }^{8}$. The literature indicates that $30 \%$ of the community-dwelling elderly suffers one or more falls each year and that nursing home residents are approximately three times more likely to fall compared with their community-dwelling counterparts ${ }^{9}$. The intrinsic risk factors for falls are generally recognized,

Corresponding author: Marcos Eduardo Scheicher. Address: Av Hygino Muzzi Filho, 737, Marília, SP, Brasil. Email: marcos.scheicher@unesp.br

1 Programa de Pós-Graduação em Desenvolvimento Humano e Tecnologias, Instituto de Biociências, UNESP, Rio Claro, São Paulo, Brasil

${ }^{2}$ Curso de Fisioterapia, Faculdade de Ensino Superior do Interior Paulista (FAIP), Marília (SP), Brasil

${ }^{3}$ Departamento de Fisioterapia e Terapia Ocupacional, Faculdade de Filosofia e Ciências, Universidade Estadual Paulista (UNESP), Marília (SP), Brasil. Programa de Pós-Graduação em Desenvolvimento Humano e Tecnologias, Instituto de Biociências, UNESP, Rio Claro, São Paulo, Brasil

Financial support: nothing to declare.

Submission date 24 April 2019; Acceptance date 05 June 2019; Publication date xx Mês xxxx 
such as age, functional disabilities, chronic diseases, gait disturbances, and fear of falling ${ }^{10}$. Fall-related costs ranged between $0.85 \%$ and $1.5 \%$ of the total health care expenditures in developed countries ${ }^{11}$.

The center of pressure (COP) oscillation is commonly used as an index for postural stability ${ }^{12}$ and, in the last years, the preferred method of measuring COP has been the posturography by a force platform ${ }^{13}$. With this instrument, is possible evaluate the COP trajectories in the frontal plane ( $X$-direction) and sagittal plane ( $Y$-direction), the velocity of body oscillation and the body displacement area by the center of pressure (COP) related to the support base. From a biomechanical perspective, COP provides a first approximation to the location of the body's center of mass over the standing surface, and an increased COP fluctuation is taken as a sign of poor balance control ${ }^{14}$. Balance tests based on force platform registrations indicate changes in balance among older subjects in longitudinal designs and are predictive of survival among older people ${ }^{15}$. Poor results in force platform tests are also associated with difficulties in activities of daily living functions ${ }^{16}$.

Some studies have examined the static balance of the community-dwelling elderly and in $\mathrm{NHs}^{12,17}$ using a force platform, but no studies were found using this balance assessment tool, comparing these populations. So, there is a knowledge gap in comparing the static balance between these two groups of elderly people in the same study using the posturography. Understanding how the balance and mobility of nursing home residents behave is important to improve recovery techniques and postural balance training for this population.

\section{OBJECTIVE}

To compare the static balance and mobility of nursing home residents with community-dwelling elderly and verify that confounders imply in a worse postural balance on nursing home residents.

\section{METHODS AND PROCEDURES}

This was a cross-sectional study of a convenience sample, evaluated between March and December of 2016. All volunteers of community enrolled in the study were selected in the same way: primary health units, health centers, community centers and geriatric clinics. The volunteers of nursing homes were selected in two nursing homes at a city of Marília, São Paulo, Brazil. Written informed consent was obtained from all patients before enrollment. The study was approved by the Research Ethics Committee of the Faculty of Philosophy and Sciences, Universidade Estadual Paulista (UNESP), Marília, São Paulo, Brazil, and was conducted in accordance with Resolution No. 196/96 of the National Health Council (Protocol 1.591.817).

\section{Inclusion and exclusion criteria in sample}

Subjects with neurological or musculoskeletal disorders (information extracted from medical records), pain that interfered with their daily activities, with lower extremity joint replacement, orthostatic postural hypotension, and abnormal scores on the Mini-Mental State Examination according to the educational level (20 for illiterates; 25 for schooling level of 1 to 4 years; 26.5 for 5 to 8 years; 28 for 9 to 11 years; and 29 for higher levels of education), ${ }^{18}$. were not included. In addition, participants who were using psychoactive or vasoactive medications at the time of the evaluation were also not included. The same criteria were applied to both groups.

\section{Balance evaluation}

Center of pressure (COP) data were obtained using an $\mathrm{AMTI}^{\circledR}$ force platform (AccuSway Dual Top, Watertown, MA, USA). Data were sampled at $100 \mathrm{~Hz}$ and normalized by the body mass index. The subjects completed three consecutive experiments and each attempt was recorded for $30 \mathrm{~s}$ with open and closed eyes and were instructed to remain as still as possible, barefoot, looking forward, feet not exceeding shoulder width and arms at their sides. ${ }^{19}$. The parameters were processed using the AMTI's Balance Clinic ${ }^{\circledR}$ software for clinical balance, with following calculations:

-total displacement: $\boldsymbol{l}_{\text {path }}=\sum_{i=2}^{n} \sqrt{\left(x_{i}-x_{i-t}\right)^{2}+\left(y-y_{i-t}\right)^{2}}$

- X-SD (standard deviation in the frontal plane): $x_{s d}=\frac{1}{n} * \sqrt{\sum_{i=1}^{n}\left(X_{i}-x_{\text {avg }}\right)^{2}}$

- Y-SD: standard deviation in the sagittal plane: $y_{s d}=\frac{1}{n} * \sqrt{\sum_{i=1}^{n}\left(y_{i}-y_{a v g}\right)^{2}}$

- mean velocity: $\iota_{\text {unit }}=\frac{l_{\text {path }}}{t}$

- 95\% of ellipse area: $A=\pi * \sqrt{F *\left(x_{s d}^{2}+y_{s d}^{2}+D\right)} * \sqrt{F *\left(x_{s d}^{2}+y_{s d}^{2}-D\right)}$

Mobility was evaluated by the Timed Up and Go test (TUG). The TUG has been recommended as a simple fall risk screening tool, primarily to identify people warranting more detailed assessment of mobility. ${ }^{20}$. The test measures the time (in seconds) necessary for a person to rise from a chair with armrests, walk 3 meters at a comfortable walking speed, turn, return to the chair, and sit down. According to Trueblood et al., TUG time fewer than 9 seconds indicates low risk of falls, between 10 and 13 seconds moderate risk of falls, and 14 seconds or more indicates a high risk of future falls, with good sensitivity (75\% -87\%) and specificity $(67 \%-87 \%)$ in community-dwelling older adults ${ }^{21}$. In a study, Alexandre et al. ${ }^{22}$. showed that the best predictive value for Brazilian elderly individuals was 12.47 seconds, with $73.7 \%$ sensitivity, $65.8 \%$ specificity and area under the ROC curve of 0.68 (95\% Cl:0.54-0.83). Thus, older people with values over $12.47 \mathrm{~s}$ in the TUG test have a higher risk of falling. 


\section{Statistical analysis}

The normality of the data was verified by the Shapiro-Wilk test. Comparisons were made by unpaired t-tests when the sample was considered normal and by the Mann-Whitney test when the sample was considered not normal. The relative risk of falls was evaluated by Fisher's Exact Test, considering values above $12.4 \mathrm{~s}$ for the TUG test as an increased risk of falling. Pearson or Spearman correlation analysis was performed to identify the independent variables with a significant relationship with the dependent variables. The variables that showed significant correlation were initially included in the simple linear regression analysis and R2 was analyzed to ascertain the coefficient of determination of the percentage variation. For all analyses, a value of $p<0.05$ was considered significant.

The effect size for the variables, with probability of error of $5 \%$, was: total displacement: 1.27 [Power (1- $\beta$ err prob): 0,98]; mean velocity: 0.84 [Power (1- $\beta$ err prob): 0.79]; $95 \%$ of ellipse area: 0.60 [Power (1- $\beta$ err prob): 0.47]; Timed up and Go: 0.96 [Power (1- $\beta$ err prob): 0,92].

\section{RESULTS}

Table 1 shows the characterization of the sample related to age, time of institutionalization, body mass index, and amount of medication.

Tables 2 and 3 show the mean values of the static balance variables between nursing homes residents and community with open and closed eyes, respectively.

Figure 1 shows the comparison of TUG test results between institutionalized and community-dwelling elder. The relative risk of falls based on TUG test showed that nursing home residents are 3.3 times more likely to have values greater than 12.4 s on the TUG test than community elders ( $p=0.03 ; 95 \%$ Confidence Interval $=0.93$ to 12.18 ), showing a higher risk of falls in this population.

Table 1: Study participants Characterization (data in mean \pm standard deviation).

\begin{tabular}{lccc}
\hline & Nursing Home & Community & p \\
\hline $\mathrm{N}$ & 21 & 21 & $71,4 \%$ \\
Gender (female) & $57,1 \%$ & $72.57 \pm 7.13$ & $\mathrm{~ns}$ \\
Age & $75.47 \pm 7.31$ & --- & \\
Time of institutionalization (years) & $3.67 \pm 3.37$ & $70.76 \pm 13.08$ & $\mathrm{~ns}$ \\
Weight $(\mathrm{Kg})$ & $69.57 \pm 16.24$ & $1.57 \pm 0.09$ & $\mathrm{~ns}$ \\
Height $(\mathrm{m})$ & $1.60 \pm 0.08$ & $28.43 \pm 4.52$ & $\mathrm{~ns}$ \\
BMI $\left(\mathrm{kg} / \mathrm{m}^{2}\right)$ & $26.90 \pm 5.09$ & $2.28 \pm 1.58$ & $<0.001$ \\
number of medication & $5.90 \pm 3.98$ & $\mathrm{~ns}$ \\
Number of falls (last 12 months) & $0.61 \pm 1,0$ & $0.42 \pm 0.7$ & \\
\hline
\end{tabular}

Note: Kg: kilogram, m: meters, BMI: body mass index; ns: nonsignificant

Table 2: Means and standard deviations of the center of pressure variable between institutionalized and community elderly with open eyes/firm surface.

\begin{tabular}{lcc}
\hline & Nursing Home & Community \\
\hline Mean velocity (cm/s) & $2.6 \pm 0.84$ & $1.88 \pm 0.86$ \\
X-SD (cm) & $0.60 \pm 0.18$ & 0.001 \\
Y-SD (cm) & $0.55 \pm 0.15$ & 0.015 \\
Total displacement $(\mathrm{cm})$ & $77.9 \pm 25.05$ & $52.7 \pm 12.59$ \\
$95 \%$ of ellipse area $\left(\mathrm{cm}^{2}\right)$ & $6.5 \pm 3.3$ & 0.17 \\
\hline
\end{tabular}

Note: ns: nonsignificant, X-SD: standard deviation in the frontal plane; Y-SD: standard deviation in the sagittal plane.

Table 3: Means and standard deviations of the center of pressure variable between institutionalized and community elderly with closed eyes/firm surface.

\begin{tabular}{lcc}
\hline & Nursing Home & Comunity \\
\hline Mean velocity total (cm/s) & $3.50 \pm 1.6$ & $2.28 \pm 0.9$ \\
X-SD (cm) & $0.74 \pm 0.27$ & $0.56 \pm 0.19$ \\
Y-SD (cm) & $0.63 \pm 0.17$ & $0.009 \pm 0.15$ \\
Total displacement (cm) & $104.92 \pm 49.8$ & $69.36 \pm 28.8$ \\
$95 \%$ of ellipse area $\left(\mathrm{cm}^{2}\right)$ & $9.34 \pm 5.4$ & 0.001 \\
\hline
\end{tabular}

Note: ns: nonsignificant, X-SD: standard deviation in the frontal plane; Y-SD: standard deviation in the sagittal plane. 


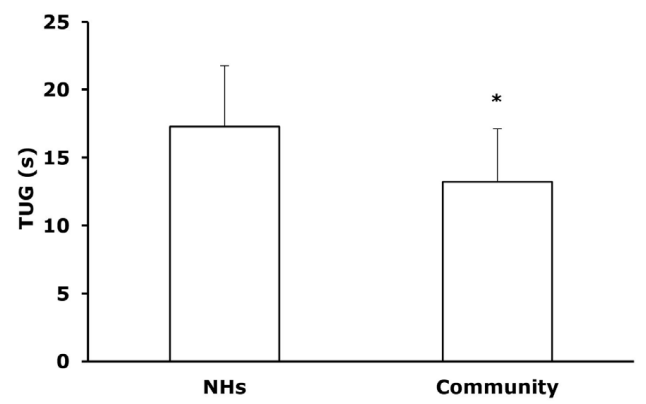

Figure 1: Comparison of TUG time between institutionalized (NHs, $n=21$, $17.28 \pm 4.5 \mathrm{~s})$ and community elderly $(n=21,13.21 \pm 3.9 \mathrm{~s}),{ }^{*}$ Note: $p=0.002$.

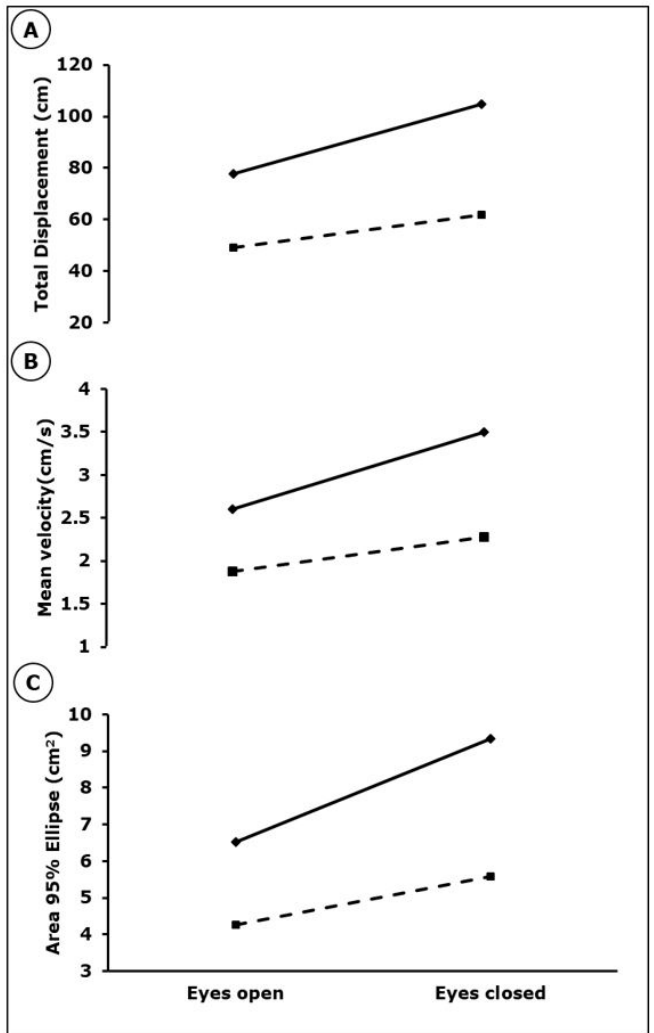

Figure 2: Influence of vision on balance in institutionalized (continuous line, $n$ $=21$ ) and community elderly (dashed line, $n=21$ ). Note: A: Total displacement, $p<0.0001 ; B$ : mean velocity, $p<0.0001 ; C$ : area $95 \%$ ellipse, $p=0.005$.

Table 4: Correlation indices between dependent variables and independent variables.

\begin{tabular}{lcccc}
\hline & \multicolumn{4}{c}{ Dependent variables } \\
\cline { 2 - 5 } & $\begin{array}{c}\text { TUG } \\
(\mathbf{s})\end{array}$ & $\begin{array}{c}\text { TD } \\
(\mathbf{c m})\end{array}$ & $\begin{array}{c}\text { MV } \\
(\mathrm{m} / \mathrm{s})\end{array}$ & $\begin{array}{c}95 \% \text { EA } \\
\left(\mathbf{c m}^{2}\right)\end{array}$ \\
\hline Age (years) & 0.10 & 0.30 & 0.32 & 0.13 \\
Gender & -0.22 & -0.26 & -0.27 & 0.07 \\
BMI $\left(\mathrm{kg} / \mathrm{m}^{2}\right)$ & 0.08 & 0.18 & 0.18 & 0.27 \\
Number of medications & $0.52^{*}$ & 0.35 & 0.36 & 0.02 \\
Number of falls (last 12 months) & 0.23 & 0.11 & 0.11 & -0.28 \\
Length of institutionalization (years) & 0.08 & 0.02 & 0.03 & -0.23 \\
\hline
\end{tabular}

Note: TUG: Timed up ad Go, BMI: body mass index, TD: total displacement, MV: mean velocity, EA: elipse area. Note: ${ }^{*} p=0.01$
The Figure 2 ( $A, B$ and $C$ ) show the variables total displacement, mean velocity and $95 \%$ of ellipse area with eyes open and closed between institutionalized and community elders. A large oscillation was observed in both groups, however, older individuals of the institutions oscillated more when visual information was withdrawn.

The correlation analysis showed that of the variables age, number of medications, BMI, number of falls and time of institutionalization, only the number of medications presented a significant value with the TUG score $(r=0.52, p=0.01)$, and no variables correlated with static equilibrium (Table 4). The linear regression analysis showed that the number of medications explained $27,7 \%$ of the TUG performance.

\section{DISCUSSION}

Our results showed that, in general, the $\mathrm{NH}$ group presented higher values in the COP oscillation than the community-dwelling elderly, indicating that this population needs a greater sway of the COP to restore body balance when compared with community elders. Generally, greater sway rises the probability of an uncontrolled crossing of stability limits $^{23}$. Briefly, compared with the community-dwelling elderly, the nursing home residents controlled their COP more unstably in the narrow base of support.

When the vision was suppressed, was observed an increasement in the COP sway of the two groups, but again, the $\mathrm{NHs}$ group presented higher values than the community group. To maintain the upright stance according to environmental changes, our Central Nervous System continually changes its emphasis (i.e., weight) on visual, vestibular and somatosensory information ${ }^{24}$. When visual information is not available (eyes closed or in a dark environment), other sources of sensory information should be used, ${ }^{4}$ what not was observed in the nursing home residents.

The same way, the time to perform the TUG test of the $\mathrm{NH}$ residents was greater than in community-dwelling elderly, suggesting a worse mobility of this population. According to Schoene et al.(2013), ${ }^{20}$ the TUG is widely recommended as a predictor of falling risks in elderly, as it identifies balance deficit and gait. In addition, the TUG involves common everyday actions, fundamental to an independent life and is easy to apply. Despite this, it is composed of complex activities for the elderly, as it should have the muscular power of lower limbs and trunk to lift and sit without support, walk 3 meters, turn $180^{\circ}$ and walk 3 meters again, being activities that need power, agility, and balance ${ }^{25}$. Therefore, lower values indicate better functional mobility, better balance, higher gait speed and, therefore, lower risk of falling, besides a greater independence in activities of daily living.

The results showed that the institutionalized elderly presented mean values above of cut-off considered normal $(12.47 \mathrm{~s})^{22}$. indicating lower muscle power, agility and balance, showing an increased risk of falling. 
The data presented corroborate the study by Yumin (2011), ${ }^{26}$ which evaluated 122 elderly people, 60 institutionalized and 62 community residents, and found significantly higher values of TUG for institutionalized elderly compared to elderly in the community.

As part of the aging process, elderly is submitted to changes, particularly with regard to postural control and for various reasons seniors living in nursing home institutions are more vulnerable to this changes.

Table 4 shows that of all independent variables evaluated, only number of medications show a significative correlation with the TUG score. There was no significant correlation between the independent variables and the static balance. There is a lack of related work in the literature using the same variables and on the same population (nursing home residentes and community-dwelling elderly), restricting a broader discussion of the results found here.

The length of institutionalization is expected to influence the postural balance due to the lack of stimuli that these elderly people experience. To the authors' surprise, this variable did not correlate with the TUG test and with the static balance variables. The study of Batista et al. ${ }^{27}$, also found no relationship between the length of institutionalization and Berg and TUG scores but found correlation with the ellipse area and with the mean speed of the COP in the $x$-axis.

Medications are an essential component of health care for many nursing home residents when are correctly administered, but harmful if not properly indicated. The number of drugs taken daily has been identified as an independent risk factor for falls. Zia et al. found that the total number of drugs was an important predictor of falls among women ${ }^{28}$. The study of Nakagawa et al.examined the relationship between the number of drugs taken and balance and found that older adults who take three or more drugs/day are at higher risk of falls, according to the Berg scale ${ }^{29}$. In the same way, our study observed the same relationship, but with the TUG test.

Some limitations have to be considered. First, due to the cross-sectional character, there is no way to correlate institutionalization with the worsening of postural balance (it is impossible to differentiate cause and effect). A longitudinal study would help to verify this relationship. Second, only elderly individuals with cognitive normality were included, both in the institutionalized and in the community group. Therefore, it is necessary to do other studies with elderly people with cognitive alterations. Third, other studies need to be carried out to evaluate the influence of other confounders on postural balance in the institutionalized population, such as the type of medication, the time that the institutionalized elderly spend sitting or lying down during the day, comorbidities and muscle strength, which were not evaluated in this study. Fourth, the visual alterations were not evaluated. In addition, it is necessary to consider the importance of other studies with a larger number of elderly people living in long-term institutions.

\section{CONCLUSION}

The results showed that the nursing home residents with a normal cognitive condition had greater center of gravity oscillation, worse mobility, and higher risk of falls than community elders. In addition, it was found that in nursing home residents, the ingestion of five or more drugs had relation with mobility.

\section{Acknowledgments:}

The authors thank the participants who volunteered for the study.

\section{AUTHOR'S CONTRIBUITIONS:}

LMF elaborated the study design and performed the data collection; LAM elaborated the study design and performed the data collection; MES performed statistical analysis and the critical intellectual revision of the manuscript. All authors read and approved the final version of the manuscript.

\section{CONFLICT OF INTEREST:}

nothing to declare.

\section{REFERENCES}

1. Horak FB. Postural orientation and equilibrium: What do we need to know about neural control of balance to prevent falls? Age Ageing. 2006;35:7-11.

2. Holtrop JL, Loucks TM, Sosnoff JJ, Sutton BP. Investigating Age-related changes in fine motor control across different effectors and the impact of white matter integrity. Neuroimage. 2014;96:81-7.

3. Linortner $P$, Jehna $M$, Johansen-berg $H$, Matthews $P$, Schmidt $R$, Fazekas $\mathrm{F}$, et al. Aging associated changes in the motor control of ankle movements in the brain. Neurobiol Aging. 2014;35(10):2222-9.

4. Antes DL, Schneider IJC, d'Orsi E. Mortality caused by accidental falls among the elderly: a time series analysis. Rev Bras Geriatr e Gerontol. 2015;18(4):769-78.

5. de Souto Barreto P, Lapeyre-Mestre M, Mathieu C, Piau C, Bouget C, Cayla $\mathrm{F}$, et al. A multicentric individually-tailored controlled trial of education and professional support to nursing home staff: research protocol and baseline data of the IQUARE study. J Nutr Health Aging. 2013 Feb 15;17(2):173-8.

6. Oliveira RG De, Tolocka RE. Inclusão social e pessoas que participam de bailes em uma instituição de longa permanência para idosos. Rev da Educ Física/UEM. 2009;20(1):85-96.

7. Ikezoe T, Asakawa Y, Shima H, Kishibuchi K, Ichihashi N. Daytime physical activity patterns and physical fitness in institutionalized elderly women: An exploratory study. Arch Gerontol Geriatr. 2013;57(2):221-5.

8. Vu MQ, Weintraub N, Rubenstein LZ. Falls in the nursing home: Are they preventable? J Am Med Dir Assoc. 2004;5(6):401-6.

9. Rubenstein LZ, Josephson KR, Robbins AS. Falls in the Nursing Home. Ann Intern Med. 1994;121(6):442-51.

10. Greenberg SA, Sullivan-Marx E, Chittams J, Cacchione PZ. Measuring fear of falling among high-risk, urban, community-dwelling older adults. Geriatr Nurs (Minneap). 2016;37(6):489-95.

11. Burns ER, Stevens JA, Lee R. The direct costs of fatal and non-fatal falls among older adults - United States. J Safety Res [Internet]. 2016;58:99103. Available from: http://dx.doi.org/10.1016/j.jsr.2016.05.001

12. Yamagata $\mathrm{M}$, Ikezoe $\mathrm{T}$, Kamiya M, Masaki M, Ichihashi N. Correlation between movement complexity during static standing and balance function in institutionalized older adults. Clin Interv Aging. 2017;12:499-503.

13. Visser JE, Carpenter MG, van der Kooij H, Bloem BR. The clinical utility of posturography. Clin Neurophysiol. 2008;119(11):2424-36. 
14. Drozdova-Statkevičienė $M$, Česnaitienè VJ, Pukènas K, Levin O, Masiulis N. Sway regularity and sway activity in older adults' upright stance are differentially affected by dual task. Neurosci Lett. 2018;666(November 2017):153-7.

15. King GW, Abreu EL, Cheng A-L, Chertoff KK, Brotto L, Kelly PJ, et al. A multimodal assessment of balance in elderly and young adults. Oncotarget. 2016;7(12).

16. Howcroft J, Lemaire E, Kofman J, Mcllroy W. Elderly fall risk prediction using static posturography. PLoS One. 2017;12(2):1-13.

17. Scheicher ME, Fonseca LCS, Bortolloto TB, de Carvalho IF. A patellar bandage improves mobility but not static balance in elderly female fallers. J Bodyw Mov Ther. 2017;1-5.

18. Brucki SMD, Nitrini R, Caramelli P, Bertolucci PHF, Okamoto IH. Sugestões para o uso do mini-exame do estado mental no Brasil. Arq Neuropsiquiatr. 2003 Sep;61(3B):777-81.

19. Duarte M, Freitas SMSF. Revision of posturography based on force plate for balance evaluation. Rev Bras Fisioter. 2010;14(3):183-92.

20. Schoene D, Wu SMS, Mikolaizak AS, Menant JC, Smith ST, Delbaere K, et al. Discriminative ability and predictive validity of the timed up and go test in identifying older people who fall: Systematic review and meta-analysis. J Am Geriatr Soc. 2013;61(2):202-8.

21. Trueblood P, Hodson-Chennault N, McCubbin A, Youngclarke D. Performance_and_Impairment_Based_Assessments_Among.1.pdf. J Geriatr Phys Ther. $2001 ; 24(1): 1-\overline{6}$.
22. Alexandre TS, Meira DM, Rico NC, Mizuta SK. Accuracy of Timed Up and Go Test for screening risk of falls among community-dwelling elderly. Brazilian J Phys Ther. 2012 Oct;16(5):381-8.

23. Błaszczyk JW. The use of force-plate posturography in the assessment of postural instability. Gait Posture. 2016;44:1-6.

24. Peterka RJ. Sensorimotor Integration in Human Postural Control. J Neurophysiol. 2002;88:1097-118.

25. Kubicki A. Functional assessment in older adults: Should we use timed up and go or gait speed test? Neurosci Lett. 2014 Aug;577:89-94.

26. Yümin ET, Şimşek TT, Sertel M, Öztürk A, Yümin M. The effect of functional mobility and balance on health-related quality of life (HRQoL) among elderly people living at home and those living in nursing home. Arch Gerontol Geriatr. 2011;52(3):e180-4.

27. Batista WO, Alves Junior E de D, Porto F, Pereira FD, Santana RF, Gurgel $\mathrm{JL}$. Influence of the length of institutionalization on older adults' postural balance and risk of falls: a transversal study. Rev Lat Am Enfermagem. 2014;22(4):645-53.

28. Zia A, Kamaruzzaman SB, Tan MP. Polypharmacy and falls in older people: Balancing evidence-based medicine against falls risk. Postgrad Med. 2015 May 4;127(3):330-7.

29. Nakagawa HB, Ferraresi JR, Prata MG, Scheicher ME. Postural balance and functional independence of elderly people according to gender and age: Cross-sectional study. Sao Paulo Med J. 2017;135(3):260-5. 